\title{
Trabalhonecessário
}

Issn: 1808 - 799X

ano 11, no $17-2013$

\section{EDUCAÇÃO E MEIO AMBIENTE: UMA ABORDAGEM ECOSSOCIALISTA}

\author{
Marcos Pinheiro Barreto ${ }^{1}$
}

\section{Resumo:}

Este artigo apresenta alguns pressupostos para fundamentar uma perspectiva crítica no campo da Educação Ambiental, considerando a formação de educadores no contexto da crise socioambiental contemporânea. Tendo em vista a existência de uma hegemonia pragmática no referido campo, traduzindo de forma conservadora a noção de sustentabilidade, o artigo discute a natureza da crise e a impossibilidade de construção de sociedades sustentáveis com a manutenção dos atuais padrões de produção, consumo e distribuição de riquezas. Defende uma aproximação entre o marxismo e as correntes mais críticas do ambientalismo, de modo a garantir um trabalho pedagógico comprometido com a formação de sujeitos sociais capazes de elaborarem estratégias educativas orientadas para a construção de uma outra possibilidade civilizatória.

Palavras chaves: formação de educadores - sustentabilidade - utopia

\section{Abstract:}

This article presents some assumptions to substantiate a critical perspective in Environmental Education, taking into account the training of educators in the context of contemporary socio-environmental crisis. Considering the existence of a pragmatic hegemony in this field, translating the notion of sustainability in a conservative way, this article discusses the nature of the crisis and the impossibility of constructing sustainable societies on current patterns of production, consumption and distribution of wealth. It defends a rapprochement among Marxism and the most critical currents of environmentalism to ensure a pedagogical work committed to forming social subjects able to develop educational strategies aimed to building another possibility of civilization.

Key words: formation of educators - sustainability - Utopia

\footnotetext{
${ }^{1}$ Professor adjunto da Faculdade de Educação da Universidade Federal Fluminense.
} 


\section{Trabalhonecessário}

Issn: 1808 - 799X

ano 11, no $17-2013$

\section{Introdução:}

O presente artigo participa de um debate no contexto de um campo que podemos chamar de Educação Ambiental. Estando ocupado nos últimos quatorze anos com a formação de professor@s, tenho procurado trabalhar, sobretudo com estudantes do curso de Pedagogia, com as relações entre Meio Ambiente e Educação, tendo em vista as possibilidades e limites de um trabalho pedagógico a partir das escolas.

Partindo do pressuposto de que vivemos, no campo em questão, o embate entre visões sociais de mundo diferentes, que percebem de modo diferenciado a crise socioambiental que vivemos, expressando-se em propostas pedagógicas coerentes com essas diferenças, buscamos desenvolver junto aos licenciandos, uma perspectiva crítica de modo a tomarem a questão ambiental em sua complexidade, articulando saberes econômicos, políticos, sociais, culturais e ecológicos.

Explorando, deste modo, o fértil debate que transita entre as polaridades de direita/esquerda, capitalismo/socialismo, modernidade/pós-modernidade, proponho encaminhá-lo de tal modo a nos ocuparmos inicialmente de um eixo reunindo as duas primeiras polarizações, para em seguida nos determos sobre outro eixo com a última dualidade. Esta intenção não pretende sugerir qualquer apartação real entre as questões suscitadas por cada uma das polaridades, sempre relacionáveis, mas obedece apenas à necessidade de organização do pensamento. 


\section{Trabalhonecessário}

Issn: 1808 - 799X

ano 11, no $17-2013$

\section{Direita/esquerda; capitalismo/socialismo.}

Embora em certos domínios do campo ambientalista se busque uma superação da polaridade direita/esquerda ${ }^{2}$, certamente motivados pelo convite pós-moderno de abandono à tradicional clivagem, como se ela não mais correspondesse à realidade das forças políticas no cenário de um mundo globalizado pós-industrial, considero indispensável defender a atualidade destas noções para estabelecermos uma fronteira, embora movediça, entre as correntes ambientalistas.

Acompanho Emir Sader ${ }^{3}$, quando renova a atualidade da distinção entre as duas posições acrescentando:

"É de esquerda quem se opõe ao capital especulativo, quem luta pelos direitos do mundo do trabalho, pela distribuição de renda, pela universalização dos direitos. De direita é quem defende os interesses do capital financeiro, quem privilegia os critérios de mercado em detrimento dos direitos da grande massa da população, que vive do seu trabalho".

Considerando satisfatórias estas indicações para a devida distinção entre o que poderíamos chamar de "verdes de esquerda" e "verdes de direita", importa tratar com mais cuidado das posições, que sem fazerem defesa doutrinária em favor do capital e do mercado, mas polemizando com o pensamento de esquerda, aparentemente confundem a distinção aqui explicitada.

O que parece sustentar a pretensão de uma "terceira via" por parte de segmentos do campo ambientalista, diz respeito às experiências do "socialismo real", marcadas pela "crença no progresso tecnológico e no desenvolvimento ilimitado das forças produtivas como caminho para a emancipação humana",

\footnotetext{
2 Loureiro (2003), discutindo os encontros e desencontros entre o ambientalismo e a esquerda, apresenta o slogan do Partido Verde alemão como emblemático desta posição; "Não somos nem de esquerda nem de direita, estamos à frente".

${ }^{3}$ Trata-se do artigo "O mundo pelo avesso" publicado no site Carta Maior, em 29/08/03.
} 


\section{Trabalhonecessário}

Issn: 1808 - 799X

ano 11, no $17-2013$

como nos sugere Loureiro ${ }^{4}$, compartilhando com o mundo capitalista uma opção industrialista e predatória, independente dos apelos ideológicos distintos. As críticas de ambientalistas em relação à matriz iluminista presente no marxismo ortodoxo, que historicamente tem postulado uma noção de progresso através do controle e domínio tecnológico sobre a natureza, concorreram para alimentar desconfianças mútuas, aparentemente incompatibilizando definitivamente o pensamento marxista com o ambientalismo. Sem subestimar a importância desta crítica, John Foster (1999) procura relativizar as acusações de antropocentrismo feitas à Marx, como tributário do mito de Prometeu ${ }^{5}$, associado à pretensão de domínio pleno da natureza, procurando demonstrar a inconsistência de parte das críticas em questão, apontando diversas passagens na obra, tanto de Marx quanto de Engels, muito próximas do ambientalismo contemporâneo. O conceito de desenvolvimento sustentável, tão caro ao ideário ambientalista, não parece tão distante do pensamento de Marx quando elaborou sua crítica ao capital;

Do ponto de vista de uma forma mais alta de sociedade, a propriedade privada do globo por indivíduos isolados parecerá tão absurda quanto a propriedade privada de um homem sobre outro. Nem mesmo numa sociedade inteira, uma nação ou mesmo todas as sociedades simultaneamente existentes juntas são proprietárias do globo. Elas são apenas posseiras, suas usufrutuárias e, como boni patres familias devem legá-lo, em melhores condições, às futuras gerações. ${ }^{6}$

Todo progresso na agricultura capitalista é um progresso na arte de roubar não só o trabalhador, mas o solo; todo progresso em aumentar a fertilidade do solo por um dado tempo é um progresso para arruinar as fontes de longa duração dessa fertilidade.(...) A produção capitalista, portanto, só desenvolve as técnicas e o grau de combinação do progresso social da produção minando, simultaneamente, as fontes originais de toda a riqueza - o solo e o trabalhador. ${ }^{7}$

\footnotetext{
${ }_{5}^{4}$ Loureiro (2003, pg.71)

${ }^{5}$ Neste artigo o autor adverte para o fato de que o mito de Prometeu, também se associa à criatividade, à revolta e à revolução, aspectos que teriam mobilizado mais a atenção de Marx do que a idéia de domínio sobre natureza.

${ }_{7}^{6}$ Segundo indicação de Foster; Marx, Capital, vol.III, p.776.

${ }^{7}$ Marx, Capital, vol.I, p.637-8.
} 


\section{Trabalhonecessário}

Issn: 1808 - 799X

ano 11, no $17-2013$

Em outra obra (2005), Foster procura demonstrar que longe de representarem passagens acidentais no pensamento de Marx, as preocupações ecológicas, se assim quisermos chamar, acompanham a produção teórica do mesmo desde os anos 40 do século XIX, quando acompanhava os trabalhos de químicos, entre eles o alemão Justos von Liebig, investigando as razões da degradação dos solos, que na Europa e nos Estados Unidos ganhavam a preocupação dos grandes empreendedores agrícolas. Foi, portanto, no contexto de uma crise provocada pelo esgotamento de minerais e da queda de fertilidade nos solos, que Liebig desenvolveu seus estudos esclarecedores sobre o papel dos nutrientes do solo (nitrogênio, fósforo e potássio) para assegurar boas colheitas. Uma segunda revolução agrícola ${ }^{8}$, ocorrida entre 1830 e 1880, estaria em marcha, inspirada nos trabalhos e pesquisas de químicos agriculturistas ${ }^{9}$, que permitiram a emergência de uma indústria de fertilizantes, além da caça imperialista de fontes de fertilizantes naturais, sobretudo ilhas ricas em guano, com os Estados Unidos explorando quase uma centena delas em diversas partes do planeta. $^{10}$

Foi o sentido crítico do trabalho deste químico alemão em relação à agricultura capitalista, por não respeitar as necessidades de reposição natural de nutrientes dos solos, mobilizados para a crescente demanda alimentar das cidades, que inspirou Marx na construção do conceito de "falha metabólica", conceito que merece a devida atenção por suas implicações para o entendimento sobre a natureza capitalista da crise ambiental já percebida no séc.XIX. Quando

\footnotetext{
${ }^{8}$ Segundo Forster, alguns historiadores consideram como uma segunda revolução agrícola as mudanças ocorridas na Grã-Bretanha, entre 1830 e 1880, associadas ao crescimento da indústria de fertilizantes e ao desenvolvimento da química de solos, com forte contribuição dos trabalhos de Liebig.(p. 210)

${ }^{9}$ Em 1838 foi fundada a Royal Agricultural Society of England, com apoio de ricos proprietários de terra, destinada a melhorar a produtividade da agricultura inglesa, estimulando as pesquisas que relacionavam química e agricultura (p.212).

${ }^{10}$ Segundo Foster, foram 94 as ilhas com intensa freqüência de aves marinhas, cujas fezes são ricas em nitrogênio e fosfatos, exploradas entre 1856 e 1903, sendo que 66 foram incorporadas ao território norte-americano.(p. 214).
} 


\section{Trabalhonecessário}

Issn: 1808 - 799X

ano 11, no $17-2013$

escreveu sua crítica ao capital, Marx conhecia bem as críticas de Liebig, entre outros estudiosos, sobre os agravos provocados nos solos com o comércio a longa distância de alimentos e fibras, caracterizando uma ruptura, ou "falha" entre cidade e campo, na medida em que eram destinados ao consumo urbano os nutrientes que deveriam retornar aos locais de plantio e pastagens, restituindo a saúde produtiva dos mesmos, e que, invariavelmente após o consumo, transformam-se em lixo e esgoto, a poluírem os solos, as águas e os ares das grandes cidades européias e norte-americanas.

O conceito de metabolismo, como nos demonstra Foster ${ }^{11}$, foi central em sua obra madura, na medida em que se encontra associado à noção de "troca material", no campo da biologia identificado com processos metabólicos de crescimento e decadência, mas na perspectiva de Marx, associado ao processo de trabalho, usando o conceito "para descrever a relação do homem com a natureza através do trabalho". Ou nos termos do próprio Marx;

"O trabalho é, antes de qualquer coisa, um processo entre o homem e a natureza, um processo pelo qual o homem, através de suas próprias ações, medeia regula e controla o metabolismo entre ele e a natureza.[...] Através desse movimento, ele atua sobre a natureza externa e a modifica, e assim simultaneamente altera sua própria natureza."12

Esta indissociabilidade entre a condição humana e as suas bases de sustentação material, enraizadas na natureza, ganha um sentido histórico quando critica a produção capitalista e seus impactos predatórios, quer na fertilidade dos solos, quer na saúde dos trabalhadores, revelando sua insustentabilidade, na medida em que;

(...) ela [a grande propriedade fundiária] produz condições que provocam uma falha irreparável no processo interdependente do metabolismo social, um metabolismo prescrito pelas leis naturais da própria vida. Isto resulta num esbulho da vitalidade do solo, que o comércio transporta muitíssimo além das fronteiras de um único país. [...] Se originalmente elas se distinguem [ a indústria e a agricultura em larga escala] pelo fato

\footnotetext{
${ }_{11}^{11}$ Op.cit.p.221

${ }^{12}$ Idem.
}

TrabalhoNecessário - www.uff.br/trabalhonecessario; Ano 11, № 17/2013. 


\title{
Trabalhonecessário
}

Issn: 1808 - 799X

ano 11, no $17-2013$

\begin{abstract}
de que a primeira deixa resíduos e arruína o poder do trabalho e portanto o poder natural do homem, ao passo que a última faz o mesmo com o poder natural do solo, elas se unem mais adiante no seu desenvolvimento, já que o sistema industrial aplicado à agricultura também debilita ali os trabalhadores, ao passo que, por seu lado, a indústria e o comércio oferecem à agricultura os meios para exaurir o solo." ${ }^{13}$
\end{abstract}

Assim, se a distância teórica entre o marxismo e o ambientalismo, não se apresenta insuperável, se considerarmos que a noção de sustentabilidade não era estranha ao pensamento marxiano, bem como a idéia de progresso irrestrito não era tão cega como já foi atribuída ao autor, convém buscarmos outras divergências, como a que se refere à premissa que atribui ao proletariado a tarefa revolucionária de superação do capitalismo, que tomada em bases ortodoxas, levou parte da esquerda a uma subestimação de outros sujeitos históricos capazes de formularem alternativas ao capitalismo. De fato, como assinala Loureiro $^{14}$, a origem histórica do movimento ambientalista em setores das classes médias, com posições invariavelmente ambivalentes em relação à contradição entre capital e trabalho, repercute até hoje no movimento sindical, embora já tenha sido mais refratário ao ideário ambientalista, com as desconfianças ${ }^{15}$ sendo aos poucos vencida com a percepção de que as pautas ambientais, imbricadas com a qualidade de vida, não são estranhas aos interesses dos trabalhadores. ${ }^{16}$

Precisamos considerar, ainda, que o colapso do "socialismo real" no Leste Europeu, concorreu decisivamente para fragilizar o ideário socialista, ao mesmo tempo em que provocava em muitos setores da esquerda mundial uma migração para outros campos teóricos, assim como revitalizou o ideário neoliberal, que cantava vitorioso o fim do socialismo, confluindo para busca de uma superação da dualidade direita/esquerda.

\footnotetext{
${ }^{13}$ Op.cit. p. 219

${ }_{15}^{14}$ Op.cit. p.67

${ }^{15}$ Vale lembrar dos debates que marcaram o retorno de exilados brasileiros no fim dos anos 70 , alguns dos quais, como Fernando Gabeira, trazendo para o cenário político nacional questões referentes à ecologia e à sexualidade, encontrando forte resistência dos setores mais ortodoxos da esquerda brasileira.

${ }^{16}$ No caso brasileiro, vale registrar como o conceito de Justiça Ambiental tem sido trabalhado pela Central Única dos Trabalhadores (CUT), in Martins (2004) e Neto (2004).
} 


\section{Trabalhonecessário}

Issn: 1808 - 799X

ano 11, no $17-2013$

O "defensivismo" progressivamente assumido pelo movimento operáriosindical, como nos sugere Mészáros(2002) ${ }^{17}$, resultante do caráter setorial e parcial das lutas encaminhadas de forma centralizada e burocratizada por centrais sindicais e partidos políticos historicamente ligados ao ideário socialista, garantiu no pós-guerra a adesão política aos "Estados de Bem-Estar", como interlocutores legalmente constituídos, regrando e limitando, segundo a lógica da expansão capitalista, as expectativas e os direitos dos trabalhadores. Este processo de abandono do caráter utópico e revolucionário do movimento socialista e de sua base social operária é identificado também por Antunes (2001:40), quando acusa "um processo político e ideológico de socialdemocratização da esquerda", atingindo fortemente o sindicalismo de esquerda, sobretudo a partir da crise dos "Estados de Bem-Estar" e a sua superação pela agenda neoliberal afinada com o as novas exigências do capital globalizado, caracterizando, na virada do século, uma "regressão da própria socialdemocracia". Movimentos sindicais, outrora identificados com a socialdemocracia ou com o socialismo, assumem pressupostos do ideário neoliberal, co-patrocinando, tanto nos países centrais como nos periféricos, reformas que tem atingido duramente os direitos sociais e econômicos de trabalhadores e afetando as políticas públicas sociais dos governos, favorecendo o cultivo de uma atitude complacente e resignada por parte dos movimentos sociais de um modo geral.

Os efeitos da crise do pensamento de esquerda, articulada com avanço do neoliberalismo em relação ao campo ambientalista, se traduziram, segundo Loureiro (2000), na subestimação das contradições entre capital e trabalho e na valorização das chamadas "questões universais", entendendo que os riscos ambientais planetários se sobrepõem aos interesses de classes, naturalizando de certa forma o capitalismo como sistema societário e, como conseqüência,

\footnotetext{
${ }^{17}$ No prefácio à edição brasileira de sua obra "Para além do capital".
} 


\section{Trabalhonecessário}

Issn: 1808 - 799X

ano 11, no $17-2013$

apostando em mudanças pragmáticas, no sentido do "aprimoramento" da democracia e da cidadania, através de ações políticas e educativas locais e cotidianas, sem estabelecerem maiores relações com a crise estrutural das sociedades contemporâneas. Deste modo, ao desvincular os nexos entre capital, trabalho e meio ambiente para compreender a natureza da crise que ora vivemos, desconsiderando a importância da tradição crítica do marxismo para tanto e sublimando as contradições das sociedades capitalistas, setores ponderáveis do campo ambientalista acabam fazendo coro com a sinfonia pós-moderna para afastar, como questão superada, a necessidade histórica de um projeto civilizatório de inspiração socialista.

Reafirmando, assim, como sugere Mészáros ${ }^{18}$, "a atualidade histórica da ofensiva socialista", diante do malogro do defensivismo e da falência dos "Estados de Bem-Estar", considerando portanto oportuna as clivagens direita/esquerda, capitalismo/socialismo, passo a discutir a insustentabilidade do projeto civilizatório em bases capitalistas, tendo em vista o caráter destrutivo do mesmo, quer consideremos seus impactos sobre o mundo do trabalho, quer sobre o meio ambiente.

Contra a expectativa, algo conformada, de segmentos da esquerda e de ambientalistas, que mesmo (parcialmente) críticos à lógica capitalista, parecem acreditar na possibilidade de dotá-la de uma sensibilidade social e ambiental de modo a transitarmos pacificamente para um modelo de "desenvolvimento sustentável", podemos considerar a oportuna análise que faz Antunes (2001), para quem as transformações que marcaram o mundo contemporâneo nas últimas duas décadas, impulsionadas pela reestruturação produtiva e pelo neoliberalismo, são dotadas de um caráter destrutivo, sendo que duas das suas manifestações são ...

\footnotetext{
${ }^{18}$ Op.cit. p.24
} 


\title{
Trabalhonecessário
}

Issn: 1808 - 799X

ano 11, no $17-2013$

\begin{abstract}
"mais virulentas e graves: a destruição e/ou precarização, sem paralelos em toda a era moderna, da força humana que trabalha e a degradação crescente, na relação metabólica entre homem e natureza, conduzida pela lógica voltada prioritariamente para a produção de mercadorias que destroem o meio ambiente.."19
\end{abstract}

Se considerarmos, como o autor, que este cenário de "aguda destrutividade" expressa a natureza estrutural de uma crise sem precedentes e que as dimensões sociais e ambientais não podem ser dissociadas, sob pena de não percebermos a lógica do que Mészáros chama de "sistema de sociometabolismo do capital" e sua tendência de autodestruição, no limite, nos avizinhando da própria destruição global da humanidade, não podemos ceder aos apelos de um "desenvolvimento sustentável", tão freqüentemente apregoado por projetos sócio-educativos associados à Educação Ambiental.

O que estes e outros autores, que trabalham no campo do materialismo histórico, procuram demonstrar e que não podem ser desconsiderados pelos setores mais críticos do ambientalismo, é que não estamos diante de uma mera crise cíclica do capitalismo, na medida em que o processo de "mundialização do capital", iniciado nos anos 80, como nos adverte Chesnais (1999), implicou em mudanças no padrão de acumulação fordista, que caracterizou o desenvolvimento capitalista no pós-guerra, em favor de "um regime de acumulação financeirizada mundial", conceito interessante para caracterizar a crescente hegemonia do capital financeiro sobre aqueles de origem industrial ou comercial. Este regime de acumulação tem como epicentros os grandes centros financeiros, ligados em tempo real pelas novas tecnologias de informação, tendo como principais protagonistas as corporações de alcance global, as antigas "multinacionais", agora sob a forma de grandes grupos financeiros, ainda que de base industrial, com crescente atuação nos mercados de câmbio, sendo responsáveis por 2/3 das trocas internacionais de bens e serviços. ${ }^{20}$ Movida por um movimento essencialmente especulativo, privilegiando ganhos de curto prazo no mercado

\footnotetext{
${ }^{19}$ Op.cit.p. 38.

${ }^{20}$ Op.cit. p.85
}

TrabalhoNecessário - www.uff.br/trabalhonecessario; Ano 11, № 17/2013. 


\section{Trabalhonecessário}

Issn: 1808 - 799X

ano 11, no $17-2013$

financeiro em detrimento de investimentos propriamente produtivos, esta autêntica "economia de cassino", como a batiza Harvey (1992:300), se permitiu a formação de uma "pequena nobreza" ${ }^{21}$ nos países centrais ligada aos negócios e serviços financeiros com as oportunidades de ganhos fáceis, tem produzido impactos severos sobretudo nos países periféricos.

Para demonstrarmos a natureza da crise atual e a conseqüente insustentabilidade do padrão de acumulação capitalista pós-fordista, podemos recorrer a dois aspectos assinalados por Chesnais ${ }^{22}$, quando acusa;

$\checkmark$ o aumento do desemprego em massa, combinado com a chamada "flexibilização" das condições de trabalho que se traduzem em precarização de direitos e de contratos, atingindo mais duramente os países periféricos;

$\checkmark$ o aumento das desigualdades entre países, assim como em relação às classes sociais dentro dos países individualmente.

Longe de se constituírem em impactos conjunturais, tais acontecimentos expressam contradições profundas e insanáveis, na medida em que o capital mundializado "concentra nas mãos de um número cada vez menor de grupos econômicos o conhecimento, a tecnologia, a riqueza e o poder sobre a vida humana, ampliando de forma escandalosa o apartheid social entre as nações e dentro delas", como afirma Frigotto (2001) para desautorizar qualquer ilusão sobre as possibilidades dos "países periféricos e semi-periféricos saírem desta situação", pois a tendência é de aprofundamento das desigualdades, face à "incontrolabilidade destrutiva" 23 que assume hoje o projeto "civilizatório" capitalista, intensificando o processo de "dessociabilização" ${ }^{24}$ da produção de riquezas, com a precarização da força humana que trabalha e a deslegitimação de direitos sociais, assim como recrudescendo a divisão internacional do trabalho

${ }^{21} \mathrm{O}$ autor se refere aos jovens executivos de grandes corporações identificados com a cultura yuppie.

22 Op. cit. p. 78

${ }^{23}$ Noção desenvolvida por Mészáros (Op.cit. p.226)

${ }^{24}$ Esta noção é trabalhada por Antunes (2001:38), quando discute os efeitos predatórios da crise capital sobre o trabalho, os direitos sociais, assim como sobre o meio ambiente. 


\section{Trabalhonecessário}

Issn: 1808 - 799X

ano 11, no $17-2013$

em prejuízo de nações africanas, asiáticas e latino-americanas, que perdem progressivamente o controle de seus mercados internos e de seus recursos naturais para grandes e poucas corporações transnacionais dos países centrais, sob o peso de chantagens financeiras ou militares.

Admitir, portanto, como fazem os setores mais pragmáticos do campo ambientalista, a possibilidade de uma transição sem rupturas para um modelo de desenvolvimento sustentável, exige o abandono do conceito de trabalho e de sua materialidade contemporânea, de modo a reduzir a crise à sua dimensão ambiental e manter, assim, alguma expectativa civilizatória por parte do capital, introduzindo soluções tecnológicas "limpas" e educando a sociedade para uma relação menos destrutiva com a natureza.

Tanto quanto em relação à "força humana que trabalha", o "meio ambiente" está sujeito a mesma "incontrolabilidade" do capital, não apenas se considerarmos a acelerada dilapidação dos recursos naturais, a crescente contaminação dos solos, das águas e da atmosfera, ameaçando a sobrevivência de gerações futuras, mas também considerando o vertiginoso processo de privatização em escala planetária dos recursos naturais, mercantilizando as mais elementares necessidades humanas.

Entendendo como Frigotto, que a "anatomia do capital mundializado" pouco tem a oferecer, "senão mais barbárie e aniquilamento das bases sociais e materiais da vida" ${ }^{\text {, }}$, impõe-se, quando não por uma questão de sobrevivência, a defesa de uma superação da lógica capitalista em favor de um projeto civilizatório alternativo, reivindicado por alguns setores do ambientalismo, como expressão de uma "sustentabilidade emancipatória", que liberte as sociedades e a natureza da tirania do capital. Para encontrar o lugar de tal utopia, nos encontros e desencontros entre o marxismo e o ambientalismo, trataremos a seguir das tensões referentes à polarização modernidade/pós-modernidade.

${ }^{25}$ Op.cit. p.39.

TrabalhoNecessário - www.uff.br/trabalhonecessario; Ano 11, № 17/2013. 


\section{Trabalhonecessário}

Issn: 1808 - 799X

ano 11, no $17-2013$

\section{Modernidade / Pós-Modernidade}

Sem pretensões de fazer justiça ao caráter multifacetado do que hoje poderíamos chamar de uma "cultura pós-moderna", que se manifesta em múltiplos campos de conhecimento, assim como nas práticas econômicas, políticas e sociais que ganham crescente hegemonia nas sociedades contemporâneas, julgo pertinente resgatar, com a ajuda do historiador Perry Anderson (1999), o sentido histórico da emergência do conceito de pósmodernidade em contraposição ao de modernidade.

Segundo Anderson, será nos anos 70 que a noção de pós-modernidade ganhará difusão, quando um crítico literário de origem egípcia, Ihab Hassan, usa o conceito para caraterizar as tendências que nas artes visuais, na música ou na tecnologia rejeitavam o paradigma modernista, para sugerir "um tipo diferente de acomodação entre a arte e a sociedade", vale dizer entre arte e mercado, livre de constrangimentos ideológicos, proclamando superadas as noções de esquerda e direita, base e suprestrutura, produção e reprodução etc... ${ }^{26}$.

Ainda no final da década, o emblema "pós-moderno" ganhará estatuto filosófico com a obra de J. F. Lyotard ${ }^{27}$, que enaltecerá a emergência de uma sociedade pós-industrial, que tem no conhecimento a principal força econômica, não mais concebida como uma totalidade orgânica, como queriam os funcionalistas, ou como campo de lutas de classes, como defendem os marxistas, mas como uma nova sociabilidade definida pela temporalidade dos contratos "em todas as áreas da existência humana - a ocupacional, a emocional, a sexual, a política - redefinidas de modo mais econômico, criativo e flexível. Assim proclama a falência de todas as narrativas grandiosas da modernidade, embora tivesse como alvo privilegiado, como assinala Anderson, o socialismo clássico.

\footnotetext{
${ }^{26}$ Anderson (1999, p. 26).

27 Trata-se da obra "A condição pós-moderna", publicada na França em 1979.
} 


\section{Trabalhonecessário}

Issn: 1808 - 799X

ano 11, no $17-2013$

Deste modo, como sugere Foster (1999), certa coerência parece indicar que sob o significado de pós-modernismo teremos um jogo de três negações básicas; contra a totalização, contra a teleologia e contra qualquer forma de utopia, resultando numa "abordagem descentralizada, caótica mesmo, da sociedade, que é vista como inerentemente fragmentada" ${ }^{28}$. No limite desta investida contra o humanismo moderno, teríamos a morte epistêmica do homem, desautorizando qualquer pretensão científica das chamadas ciências sociais, transformadas em saberes/poderes, igualmente válidos na atitude de abandono de qualquer práxis social inspirada em projetos societários globais e alternativos ao processo de globalização do capital em curso, com os conceitos de revolução, emancipação e libertação sendo silenciados, pois se trata também da "morte" da história, como expressão de um devir humano comum, em favor de uma multiplicidade de histórias evocando novas identidades/subjetividades sociais como as mulheres, negros, homossexuais, imigrantes, minorias étnicas....Para tanto, precisamos supor, como indica Cardoso (2001), "uma sociedade fragmentada em subculturas, numa ausência de horizontes holísticos, coletivos, bem como da possibilidade de qualquer tipo de mobilização global".

Ainda acompanhando Anderson para apreendermos o sentido histórico da pós-modernidade, teremos a crítica de F. Jameson(2001), que propõe a "ancoragem" do pós-modernismo nas mudanças que marcavam o metabolismo do capital, expressas na agenda neoliberal. Não se tratava mais de uma discussão empenhada na ruptura estética ou epistemológica em relação à modernidade - "a pós-modernidade torna-se o sinal cultural de um novo estágio na história do modo de produção reinante". ${ }^{29}$

Se parece inquestionável, no cenário de unificação eletrônica do planeta que garante a difusão em tempo real de produtos culturais, a cumplicidade do pós-modernismo com a lógica do mercado e do espetáculo, apresentando-se,

\footnotetext{
${ }^{28}$ Op.cit. p.197.

${ }^{29}$ Op.cit. p. 66.
}

TrabalhoNecessário - www.uff.br/trabalhonecessario; Ano 11, № 17/2013. 


\section{Trabalhonecessário}

Issn: 1808 - 799X

ano $11, \mathrm{n}=17-2013$

segundo Jameson, como "o primeiro estilo global especificamente norteamericano"30, merecendo profunda recusa pelo caráter totalitário com que se reveste, pretendo nos limites deste trabalho examinar as tensões que as teses pós-modernas tem provocado no debate entre o marxismo e o ambientalismo, sobretudo quando se discute as possibilidades e limites de um modelo de desenvolvimento realmente sustentável.

Ao fazer um balanço do materialismo histórico e acusando sua crise paradigmática diante dos vertiginosos acontecimentos que alteraram 0 "sociometabolismo do capital" e da correspondente hegemonia neoliberal, aparentemente sepultando a utopia socialista, Michael Löwy (1998), apresenta três debilidades importantes a serem superadas pelo marxismo, devidamente apontadas e criticadas pelo ambientalismo, assim como por outros movimentos sociais que se aproximaram da "cultura pós-moderna".

O primeiro limite, como prefere Löwy, diz respeito "a ignorância ou a subestimação das formas não-econômicas de dominação", para se referir às lutas sociais que acusam as opressões de gênero, raça, nacionalidade ou religião. A centralidade da crítica marxista ao capitalismo, explorando a contradição capital/trabalho no espaço da produção e conseqüentemente os mecanismos de exploração e opressão de trabalhadores assalariados, deixava de contemplar, já nos anos 60, a emergência de novos movimentos sociais de mulheres, negros, camponeses, minorias étnicas, estudantes, assim como os de natureza ecológica, que encontrarão fundamentos teóricos e filosóficos em outros campos teóricos, de onde se produziram formulações identificadas com o pós-modernismo. As novas identidades sociais que emergem destas lutas encontraram inspiração menos em Marx, do que em M. Foucault, F. Guattari, E. Morin, G. Deleuze, J. Habermas, além do citado Lyotard, para falar de alguns autores que atraíram muitos

\footnotetext{
${ }^{30}$ Op.cit. p. 76 e 77.
}

TrabalhoNecessário - www.uff.br/trabalhonecessario; Ano 11, № 17/2013. 


\section{Trabalhonecessário}

Issn: 1808 - 799X

ano 11, no $17-2013$

intelectuais que migraram do campo da esquerda clássica e que são identificados com a pós-modernidade.

A crítica ao economicismo dos marxismos identificados com o "realismo socialista", abria espaço para a manifestação de outros sujeitos sociais, e aqui Löwy aponta outro limite, subjacente ao primeiro, o da "redução do sujeito revolucionário somente à classe operária", secundarizando o protagonismo de movimento sociais que atuam menos na esfera da produção e mais na esfera da reprodução da sociedade. As mudanças na sociabilidade do capital, com profundas mudanças no mundo do trabalho e multifacetando a própria identidade dos trabalhadores, abalaram decisivamente a promessa revolucionária a ser realizada por este sujeito coletivo, a classe operária, cujas formas de organização, em partidos ou sindicatos, sofreram um processo de domesticação à medida que cediam terreno às novas exigências da acumulação flexível do capital. Mútuas desconfianças afastam ainda as posições entre marxistas e segmentos organizados da chamada sociedade civil, com os primeiros sustentando uma certa hierarquia, com mais ou menos ortodoxia, em favor das determinações econômicas e da primazia do movimento sindical e operário, enquanto que os segundos afirmam o princípio das múltiplas determinações e narrativas, não necessariamente afinadas com projetos sociais de emancipação coletiva. Sem dúvida, pós-modernismo contribuiu para a compreensão das novas sensibilidades e subjetividades que não encontravam lugar na episteme moderna, por se encontrarem instrumentalizadas no liberalismo pela cidadania formal regulada pelo mercado, ou, atrofiadas no socialismo pela imposição estatal de uma subjetividade coletiva e partidária. Mas, por outro lado, a celebração da fragmentação de uma totalidade não mais possível, e, a valorização de múltiplas subjetividades sociais encerradas em territorialidades distintas, parecem ter concorrido para a "guetização" de lutas sociais, com a acentuação de perspectivas individualistas e narcísicas. 


\section{Trabalhonecessário}

Issn: 1808 - 799X

ano 11, no $17-2013$

Um terceiro importante limite do materialismo histórico é apontado ainda por Löwy, quando se refere aos "problemas ecológicos", ou seja, a subestimação dos limites e riscos ambientais como elemento fundamental para entendermos a crise do capital e seu alcance planetário. Não sem razão, o ambientalismo de modo geral tem formulado críticas, como já foi comentado, contra a vocação desenvolvimentista e industrialista das experiências do chamado "socialismo real", mas, estendendo indevidamente sua acusação de antropocentrismo predatório, ou de dominação da natureza, a todo e qualquer projeto de inspiração socialista. Investindo, assim, contra as bases epistemológicas do modernismo, que tem no humanismo antropocêntrico e na racionalidade científica do lluminismo os fundamentos de uma relação predatória entre as sociedades humanas e a natureza, certos setores do ambientalismo, organizados em ONGs, em universidades ou movimentos sociais, preconizam a emergência de uma sociedade pós-moderna, que transcenda o capital e o trabalho, o liberalismo e o socialismo.

A despeito da pertinência das críticas ao racionalismo instrumental da modernidade, de que também o marxismo é tributário, a busca de uma sociedade sustentável por tais correntes ambientalistas, como identifica Loureiro $(2003)^{31}$, acabam restringindo suas ações à "práticas particularizadas e pouco vinculadas a uma estratégia de atuação global", indicando a inconsistência teórica desta posição, que parece superestimar experiências locais e a educação ambiental como caminho para mudanças comportamentais e éticas, subestimando o caráter destrutivo do processo de globalização em curso, rompendo a dialética sugerida pelo próprio emblema dos movimentos ambientalistas: Pensar global, Agir Local. Quão mais próximo os movimentos ambientalistas estiverem de aceitar a irreversibilidade dos tempos pós-modernos, lastreado pelos princípios da acumulação privada das riquezas socialmente produzidas e do controle privado

\footnotetext{
${ }^{31}$ Op.cit. p.66.
}

TrabalhoNecessário - www.uff.br/trabalhonecessario; Ano 11, № 17/2013. 


\section{Trabalhonecessário}

Issn: 1808 - 799X

ano 11, no $17-2013$

dos recursos naturais, mais próximos estarão de abandonar irremediavelmente a dimensão emancipatória que marcou a emergência das lutas ambientais, junto com os princípios político-filosóficos da autogestão e da autonomia, em favor da participação nos projetos financiados pelo poder público ou por empresas, as parcerias tão preconizadas pelas agências multilaterais, conformando o ideário de uma educação para o desenvolvimento sustentável em bases conservadoras.

A operação filosófica realizada pelo pós-modernismo, que atinge tanto o campo ambientalista, quanto o campo marxista, decretando a morte da modernidade sob o triunfo universal do capital, como nos adverte Anderson ${ }^{32}$, resulta "no cancelamento das alternativas políticas", na medida em que "a possibilidade de outras ordens sociais era um horizonte essencial do modernismo", ou seja, falamos aqui de morte da utopia.

Contra esta perspectiva sombria, Löwy reclama uma ruptura do marxismo com a "modernidade capitalista-ocidental", que liquidou o potencial emancipatório da modernidade, retomando a utopia, com sua necessária perspectiva "românticorevolucionária" de construção de uma nova possibilidade civilizatória, não apenas "uma versão mais progressista do paradigma industrial-capitalista," mas restaurando no horizonte material e simbólico da humanidade a necessidade histórica, pois ela não morreu, de " um novo modo de vida fundado no valor de uso e na democracia socialista, nos recursos renováveis e no cuidado com a natureza, na igualdade das raças e dos sexos, na fraternidade social e na solidariedade universal ". ${ }^{33}$

No que toca aos limites deste trabalho, o de investigar as possibilidades de um terreno comum entre o ambientalismo e o marxismo, na perspectiva utópica de uma globalização contra-hegemônica, ou dito de outro modo, de uma sustentabilidade emancipatória, recorro ao conceito de "cidadania planetária", no sentido apontado por Loureiro (2003, p.58), que forjado e defendido por muitos

\footnotetext{
${ }^{32}$ Op.cit. p. 108.

${ }^{33}$ Op.cit.p. 43
}

TrabalhoNecessário - www.uff.br/trabalhonecessario; Ano 11, № 17/2013. 


\section{Trabalhonecessário}

Issn: 1808 - 799X

ano 11, no $17-2013$

movimentos sociais ${ }^{34}$, desafia de muitas maneiras a racionalidade do capital globalizado. Seja quando supõe uma "responsabilidade planetária", traduzida no respeito aos limites dos ecossistemas e às formas de vida não-humanas, como também na solidariedade entre os humanos, quando implica na crítica ao caráter privado da acumulação capitalista que combina depredação e desperdício de recursos naturais com a manutenção de profundas desigualdades entre os povos, ou quando propõe a indissociabilidade entre estratégias locais e globais de ação política. Assim, tal conceito de cidadania permite superar os reducionismos, privilegiadores dos temas locais e singulares em detrimento das determinações globais, ou os que privilegiam os temas globais, silenciando sobre os valores, identidades e interesses locais. Fertilizada por algumas correntes ambientalistas, a cidadania planetária pode romper com o antropocentrismo e a racionalidade instrumental da tradição moderna, exponenciada nos tempos pós-modernos, ao instituir a dialética entre os direitos humanos e os direitos da natureza, como também entre direitos sociais e direitos ambientais. Assim como, inspirado pela tradição universalista do marxismo, pode ainda superar os limites da atomização e do individualismo do ideário liberal, que circunscreve a cidadania no plano formal da vida política local/nacional e na competitividade do mercado de consumo, instaurando a possibilidade de ações solidárias transnacionais, no concerto de lutas que defendam o trabalho como critério de inclusão em escala global, daquelas que afirmam a injustiça das dívidas externas dos países periféricos, daquelas que sustentam a importância de um controle social dos mercados financeiros, de outras que denunciam as guerras imperialistas, como tantas outras que podem e devem irmanar os sujeitos sociais, portadores de uma sociabilidade

\footnotetext{
${ }^{34}$ Notoriamente pelos diversos movimentos sociais que têm participado dos Fóruns Sociais Mundiais ou das jornadas de lutas contra a globalização, sitiando os locais de encontro da OMC, do GAAT, do FMI e demais organismos identificados com a sustentação do atual apartheid planetário.
} 


\section{Trabalhonecessário}

Issn: 1808 - 799X

ano 11, no $17-2013$

e de uma racionalidade alternativas, que emancipem a humanidade e a natureza do projeto civilizatório capitalista.

A utopia "vermelha e verde", defendida por Löwy, baseada no pressuposto de que "a lógica capitalista do lucro e da acumulação levará nas próximas décadas, a uma crise ecológica de dimensões inimagináveis” ${ }^{35}$, sugere não apenas a possibilidade, mas a urgência de uma aproximação filosófica, teórica e política entre marxistas e ambientalistas, incorporando todos os demais movimentos sociais que tem se manifestado contra o processo de globalização hegemônico, por natureza excludente e predatório. A delimitação de um terreno comum que permita a consolidação de uma "esquerda ecológica" ${ }^{36}$, ganha um sentido estratégico neste artigo, tendo em vista as divergências que historicamente tem afastado os dois campos, mas sobretudo a perspectiva utópica , contra-hegemônica, de construção de uma outra possibilidade civilizatória, em bases não-capitalistas.

\section{Palavras finais:}

É exatamente por considerar grave a crise socioambiental planetária, que reivindicamos a importância do seu estudo e de sua crítica no contexto de cursos de formação de professores. Sem pretender superestimar o protagonismo dos professores e das escolas na reversão da crise, cultivando alguma modalidade ingênua de otimismo pedagógico, esse artigo defende a perspectiva de que as escolas, e demais espaços educativos, podem se constituir em espaços privilegiados de formação de sujeitos sociais, que advertidos da urgência de transformações profundas nos atuais padrões de produção, consumo e

\footnotetext{
${ }^{35}$ Op. cit. P. 38.

${ }^{36}$ A noção é usada por Loureiro (2003:73), quando se propõe a "estruturar os pontos em comum entre socialismo e ambientalismo.
} 


\section{Trabalhonecessário}

Issn: 1808 - 799X

ano $11, \mathrm{n}=17-2013$

distribuição de riquezas, sejam capazes de elaborarem, planejarem e praticarem estratégias sócio-educativas orientadas para a construção de uma outra possibilidade civilizatória.

Postulamos a necessidade de uma agenda ambiental crítica elaborada por professores e demais educadores que se solidarizem com as demandas sociais e ambientais, não apenas das comunidades escolares imediatamente envolvidas, como de todas as populações que tem sido espoliadas na sua qualidade de vida, mas que se solidarize também com a natureza, respeitando seus ciclos vitais e os limites ambientais de seus ecossistemas e de suas criaturas, e necessariamente, despoluindo a produtividade humana; materialmente, de suas tecnologias predatórias e de suas injustas relações de trabalho, simbolicamente, de seu ideário antropocêntrico, etnocêntrico, neocolonialista e privatista.

Se tanto é uma utopia, vermelha e verde, como defendem os ecossocialistas, mesmo que ainda não se encontre ancorada nas práticas sociais e no cotidiano das escolas brasileiras, ela cumpre o papel de estimular a imaginação política e pedagógica, encorajando e fortalecendo os sujeitos a abandonarem a resignação, a descrença ou o fatalismo em favor de uma outra possibilidade civilizatória. Compartilhar a recusa de nos rendermos à inexorabilidade de um destino humano e ambiental a serviço do capital, pode ser um terreno comum a pavimentar um diálogo entre o mundo acadêmico e prática pedagógica nas escolas, se temos em vista a participação de educadores em qualquer projeto pedagógico de vocação crítica e emancipatória. 


\section{Trabalhonecessário}

Issn: 1808 - 799X

ano 11, no $17-2013$

\section{Referências}

ANDERSON, Perry. As origens da Pós-modernidade. Rio de Janeiro: Jorge Zahar Ed., 1999.

ANTUNES, Ricardo. Trabalho e precarização na ordem neoliberal. In: GENTILI, P. e FRIGOTTO, G. A cidadania negada. Políticas de exclusão na educação e no trabalho. São Paulo: Cortez/CLACSO, 2001.

CARDOSO, Ciro F. Epistemologia pós-moderna. In: FRIGOTTO,G.; CIAVATTA, M. Teoria e educação no labirinto do capital. Petrópolis, RJ: Vozes, 2001.

CHESNAIS, F. Um programa de ruptura com o neoliberalismo. In: HELLER, Agnes e al. A crise dos paradigmas em ciências sociais e os desafios para 0 século XXI. Rio de Janeiro: Contraponto/ Corecon, 1999.

FORSTER, John B. Marx e o meio ambiente. In WOOD, Ellen M. Em defesa da história. Marxismo e pós-modernismo. Rio de Janeiro: Zahar, 1999.

. Em defesa da história. In: WOOD, Ellen M. Em defesa da história. Marxismo e pós-modernismo. Rio de Janeiro: Zahar, 1999.

A ecologia de Marx: materialismo e natureza. Rio de Janeiro: Civilização Brasileira, 2005.

FRIGOTTO, Gaudêncio. A nova e a velha faces da crise do capital e o labirinto dos referenciais teóricos. In: FRIGOTTO,G.; CIAVATTA, M. Teoria e educação no labirinto do capital. Petrópolis, RJ: Vozes, 2001. 


\section{Trabalhonecessário}

Issn: 1808 - 799X

ano 11, no $17-2013$

HARVEY, David. A condição pós-moderna. In: A condição pós-moderna. São Paulo: Loyla, 1992.

JAMESON, Fredric. Globalização e estratégia política. In: JAMESON, F. A cultura do dinheiro. Petrópolis, RJ, Vozes, 2001.

LOUREIRO, Carlos Frederico B. Teoria Social e Questão Ambiental: pressupostos para uma práxis crítica em educação ambiental. In : LOUREIRO e outros. Sociedade e Meio Ambiente: a educação ambiental em debate. São Paulo: Cortez editora, 2000.

\section{O Movimento Ambientalista e o Pensamento}

Crítico: uma abordagem política. Rio de Janeiro: Quartet, 2003.

LÖWY, Michael. Além do neoliberalismo: a alternativa socialista. In: MALAGUTI, M. e al. Neoliberalismo: a tragédia do nosso tempo. São Paulo: Cortez, 1998.

MARTINS, Paulo R. Justiça ambiental e projeto político: o caso da Central Única dos Trabalhadores. In: ACSERAD, $\mathrm{H}$ e outros. Justiça Ambiental e Cidadania. Rio de Janeiro: Relume Dumará, 2004.

MÉSZÁROS, István. Para além do capital. São Paulo: Boitempo, 2002.

NETO, Temístocles M. Sindicalismo e Justiça ambiental. In: ACSERAD, H e outros. Justiça Ambiental e Cidadania. Rio de Janeiro: Relume Dumará, 2004.

SANTOS, Boaventura S. Pela mão de Alice. O social e o político na pósmodernidade. São Paulo; Cortez, 1985. 


\section{Trabalhonecessário}

Issn: 1808 - 799X

ano 11, no $17-2013$

Os processos de globalização. In: SANTOS, B.S.(org) A

globalização e as ciências sociais. São Paulo: Cortez, 2002.

Data de recebimento: 30/09/2013

Data de aprovação: 26/12/2013 